\title{
Study of negative symptoms in schizophrenia
}

\author{
Phanikanth Kondaparthi ${ }^{1}$, Sai Krishna Puli ${ }^{2 *}$, Datt $\mathbf{M}^{3}$
}

${ }^{\mathbf{1}}$ Assistant Professor, ${ }^{\mathbf{2}, 3}$ Professor, Dept. of Psychiatry, ${ }^{\mathbf{1}}$ Institute of Mental Health, Erragadda, Hyderabad, Telangana, ${ }^{2}$ Prathima Institute of Medical Sciences, Karimnagar, Telangana, ${ }^{3}$ Kamineni Institute of Medical Sciences, Narketpally, Nalgonda, Telangana, India

\section{*Corresponding Author: Sai Krishna Puli}

Email: kannap103@gmail.com

\begin{abstract}
Introduction: Schizophrenia is a major mental illness that can afflict and corrupt the normal functions of powerful mind. Schizophrenia is a chronic relapsing disorder with incomplete remissions. It is characterized by a diverse set of signs and symptoms which include positive, negative, cognitive, disorganization, mood and motor symptom dimensions.

Aims: The current study was aimed to study the negative symptoms in schizophrenia in patients attending a rural teaching hospital and its relation to demographic parameters, severity of illness and follow up changes.

Setting and Design: This is a cross-sectional study done in a rural medical college of Telangana state. The sample size consisted of 50 Schizophrenia subjects.

Materials and Methods: The socio-demographic data was recorded on intake proforma and psychiatric morbidity was assessed using Brief Psychiatric Rating Scale (BPRS). Negative symptoms were assessed on Scale for Assessment of Negative Symptoms(SANS).

Results: In the study sample of 50 schizophrenia subjects, 35(70\%) subjects were having gradual onset of symptoms, $13(26 \%)$ subjects were having illness from past 24 months, 26(52\%) subjects were treatment naïve, $8(16 \%)$ relapse subjects and $16(32 \%)$ were on regular maintenance treatment. The pattern of negative symptoms 34(68\%) were having flat affect, $32(64 \%)$ alogia, 40 (80\%) avolition, 38 (76\%) anhedonia, $36(72 \%)$ were having inattention. On SANS, most marked negative symptom is impersistence at work. In the present study negative symptoms were more often seen in unmarried subjects, literate subjects, unemployed subjects, joint families, gradual onset of illness, duration of illness between 13-24 months and in relapse cases. BPRS and SANS scores improved on follow up evaluations after initiation of treatment ( $\mathrm{p}$ value $<0.05$ ).

Conclusion: In the present study negative symptoms had a significant association with demographic parameters like education and occupation. In majority of the subjects, duration of illness is less than one year and the negative symptoms started quite early in the course of the disease contrary to the popular evidence. In the present study there is an equal distribution of symptoms in all five domains of negative symptoms with 'avolition' at the top. Clinically negative symptoms were missed in few subjects, as is the case in general. So, it is advisable to employ standard rating scales in all clinical evaluations, lest one should overlook the negative symptoms. Follow up evaluations in all showed the negative symptoms responding effectively to treatment, contrary to the existing evidence regarding their refractoriness.
\end{abstract}

Keywords: Schizophrenia, Negative symptoms, SANS.

\section{Introduction}

Schizophrenia is a major mental illness that can afflict and corrupt the normal functions of powerful mind. It is an enigmatic mental disorder that severely impacts the way people think, feel and act, robbing away their insight and touch with reality. ${ }^{1}$ Across the world millions of people suffer from schizophrenia. No culture, race or society is free from this malady. There is no gender immunity either.

In India, for a population of nearly one billion, an estimated four million people suffer from schizophrenia. ${ }^{2}$ Today, with a considerable lifetime morbidity and high mortality from suicide, schizophrenia is a serious public health problem and is among the top ten leading causes of disease related disability in the world. ${ }^{3,4}$ Schizophrenia is not just a bane to the sufferer, but a gigantic burden to the society as well.

Down the centuries schizophrenia entailed a lot of social stigma due to superstitions. Today, despite growing awareness, the situation is no better. Since times immemorial, schizophrenia is known to the mankind in the names of 'lunacy', 'insanity' or 'madness'. But a serious and scientific investigation of this condition began only in mid to late nineteenth century.
Ever since Eugen Bleuler coined the term schizophrenia, meaning split mind, to describe the disorder, a lot of water has flown under the bridge. ${ }^{5}$ Incessant research is ongoing in this field to understand the etiopathogenesis and phenomenology of schizophrenia for the sake of better diagnosis and management. Perhaps because of the complex heterogeneity in psychopathology and lack of precise diagnostic specificity, schizophrenia is still as much an enigma as ever. No doubt, advances in pharmacotherapy and psychosocial interventions did improve the management of schizophrenia to certain extent but the core issues still remain unanswered.

Efforts so far, to unravel the mystery of schizophrenia, only succeeded in creating semantic jargon rather than reaching any meaningful conclusions, resulting in more confusion than clarity. ${ }^{6}$ The present study attempts to make a foray into the domain of negative symptoms in schizophrenia to record our experience and results.

\section{Aims and Objectives}

The current study was aimed to

a. To study the negative symptoms in schizophrenia in patients attending a rural teaching hospital. 
b. To study the relation between negative symptoms and demographic parameters.

c. To study the relationship between negative symptoms and severity of illness.

d. To study the status of negative symptoms on two follow up visits.

\section{Materials and Methods}

A cross sectional observational study was conducted among diagnosed cases of schizophrenia patients attending a rural teaching hospital, in Telangana. The study duration was from October 2011 to September 2012.

Schizophrenic subjects diagnosed as per the International Classification of Diseases 10 (ICD-10), ${ }^{7}$ and between age groups 15-65 years, belonging to both sexes were included. Informed consent of each participant was taken. Those not willing to give valid consent and subjects with negative symptoms due to causes other than schizophrenia, co-morbidity with any serious physical illness were also excluded. ${ }^{8-10}$

Psychiatric morbidity was evaluated by using Brief Psychiatric Rating Scale (BPRS). ${ }^{11}$ BPRS was first introduced by Overall and Gorham (1962) with 16 items. It is a brief scale measuring psychopathology in psychotic patients, particularly schizophrenia. The most commonly used version is with 18 items devised by Overall and Klett(1972). ${ }^{12}$ Each item is rated on a 0 to 6 point scale ranging between not present to extremely severe. Rating is based upon observations made by clinician and subjects verbal report. Strengths of the scale include its brevity, ease of administration, wide use in research, well established validity and reliability. BPRS is appropriate for evaluating baseline psychopathology, clinical outcome and treatment response. The severity of psychopathology on BPRS is considered as 0-30 not significant, 31-40 mild illness, 41-52 moderate illness, 53 and above as severe illness.

Scale for Assessment of Negative Symptoms (SANS) was developed by N.Andreasen ${ }^{13-15}$ to assess negative symptoms in schizophrenia among the five domains of affective flattening, alogia, avolition, anhedonia and inattention. ${ }^{16,17}$ The scale consists of 24 items of which 5 are on global assessment. Clinical rating is done on direct observation over a 0 to 5 point scale ranging between none to severe. Strength of SANS includes its ease of administration and well researched reliability. SANS is often employed in assessing baseline clinical status and changes over a period of time.

Data collection was done after approval from Institutional Ethics Committee. Frequency analysis was done as a part of descriptive statistics, to describe the sample in terms of socio-demographic and clinical characteristics. Subsequently, chi-square test and t-test were used where ever appropriate.

\section{Methodology}

Subjects attending psychiatry OPD fulfilling the study criteria are enrolled into the study. Diagnosis was made by a qualified psychiatrist after applying ICD-10 criteria for schizophrenia. Then subjects are screened to rule out causes for negative symptoms other than schizophrenia. Sociodemographic data and psychosocial history were recorded on intake proforma. Subjects were rated on BPRS for severity of illness and on SANS for negative symptoms on day 1 (basal evaluation). Subjects were again evaluated after second and fourth weeks (follow up evaluation). The data collected was entered in excel sheets. Statistical analysis was done by using SPSS 22.

\section{Results and Discussion}

The study sample included 50 subjects. Of them $34(68 \%)$ subjects were between 15-35 years age, 28 (56\%) were males and 22(44\%) were females. Among them 26(52\%) were married, $40(80 \%)$ are from rural background, $36(72 \%)$ were literates, $33(66 \%)$ were unemployed, 36(72\%) from nuclear family [Table 1].

Table 1

\begin{tabular}{|c|c|c|c|c|}
\hline S. No & Parameter & $\begin{array}{c}\text { Males } \\
\mathrm{n}=28(56 \%)\end{array}$ & $\begin{array}{c}\text { Females } \\
n=28(56 \%)\end{array}$ & $\begin{array}{c}\text { Total } \\
n=50(100 \%)\end{array}$ \\
\hline 1 & $\begin{array}{ll}\text { Age } & \text { group (in years) } \\
\text { a. } & 15-25 \\
\text { b. } & 26-35 \\
\text { c. } & 36-45 \\
\text { d. } & 46-55 \\
\text { e. } & 56-65 \\
\end{array}$ & $\begin{array}{c}15(53.57) \\
10(35.71) \\
3(10.72) \\
0 \\
0 \\
\end{array}$ & $\begin{array}{l}4(18.18) \\
5(22.73) \\
4(18.18) \\
5(22.73) \\
4(18.18)\end{array}$ & $\begin{array}{l}19(38) \\
15(30) \\
7(14) \\
5(10) \\
4(8) \\
\end{array}$ \\
\hline 2 & $\begin{array}{l}\text { Marital status } \\
\text { a. Unmarried } \\
\text { b. Married } \\
\text { c. Others (separated) }\end{array}$ & $\begin{array}{c}12(42.86) \\
13(46.42) \\
3(10.72)\end{array}$ & $\begin{array}{c}3(13.64) \\
13(59.09) \\
6(27.27) \\
\end{array}$ & $\begin{array}{c}15(30) \\
26(52) \\
9(18)\end{array}$ \\
\hline 3 & $\begin{array}{l}\text { Education } \\
\text { a. Illiterate } \\
\text { b. School } \\
\text { c. Intermediate } \\
\text { d. Graduation } \\
\end{array}$ & $\begin{array}{c}3(10.72) \\
12(42.86) \\
4(14.28) \\
9(32.14) \\
\end{array}$ & $\begin{array}{l}11(50.00) \\
5(22.72) \\
3(13.64) \\
3(13.64) \\
\end{array}$ & $\begin{array}{l}14(28) \\
17(34) \\
7(14) \\
12(24) \\
\end{array}$ \\
\hline 4 & Occupation & & & \\
\hline
\end{tabular}

Telangana Journal of Psychiatry, January-June 2020:6(1):34-39 


\begin{tabular}{|l|l|c|c|c|}
\hline & a. Agriculture & $7(25)$ & $4(18.18)$ & $11(22)$ \\
& b. Professional & $1(3.57)$ & 0 & $1(2)$ \\
& c. Student & $5(17.86)$ & 0 & $5(10)$ \\
& d. Unemployed & $15(53.57)$ & $18(81.82)$ & $33(66)$ \\
\hline 5 & Family & $19(67.8)$ & $17(77.2)$ & $36(72)$ \\
& a. Nuclear & $9(32.2)$ & $3(13.6)$ & $12(24)$ \\
& b. Joint & 0 & $2(9.2)$ & $2(4)$ \\
& c. Single & & \\
\hline
\end{tabular}

Among this group 35(70\%) subjects were having gradual onset of symptoms, 13(26\%) subjects were having illness from past 24 months, 26(52\%) subjects were treatment naïve, $8(16 \%)$ relapse subjects and $16(32 \%)$ were on regular maintenance treatment. Among these fifty subjects, the pattern of negative symptoms 34(68\%) were having flat affect, 32 (64\%) alogia, 40 $(80 \%)$ avolition, 38 (76\%) anhedonia, $36(72 \%)$ were having inattention.

Table 2

\begin{tabular}{|c|c|c|c|c|}
\hline S. No & Parameter & $\begin{array}{c}\text { Males } \\
\mathbf{n}=28(\%)\end{array}$ & $\begin{array}{c}\text { Females } \\
\mathbf{n}=\mathbf{2 8}(\%)\end{array}$ & $\begin{array}{c}\text { Total } \\
\mathbf{n}=50(\%)\end{array}$ \\
\hline 1 & $\begin{array}{l}\text { Onset of symptoms } \\
\text { a. sudden } \\
\text { b. gradual }\end{array}$ & $\begin{array}{c}5(17.86) \\
23(82.14)\end{array}$ & $\begin{array}{l}10(45.45) \\
12(54.55)\end{array}$ & $\begin{array}{l}15(30) \\
35(70)\end{array}$ \\
\hline 2 & $\begin{array}{l}\text { Duration of illness (in months) } \\
\text { a. } 1-12 \\
\text { b. } 13-24 \\
\text { c. }>24\end{array}$ & $\begin{array}{c}20(71.43) \\
1(3.57) \\
7(25)\end{array}$ & $\begin{array}{c}15(68.18) \\
1(4.54) \\
6(27.28)\end{array}$ & $\begin{array}{l}35(70) \\
2(4) \\
13(26)\end{array}$ \\
\hline 3 & $\begin{array}{l}\text { Treatment status } \\
\text { a. Treatment naïve } \\
\text { b. Relapse } \\
\text { c. On treatment }\end{array}$ & $\begin{array}{l}19(67.86) \\
3(10.71) \\
6(21.43) \\
\end{array}$ & $\begin{array}{c}7(31.82) \\
5(22.73) \\
10(45.45)\end{array}$ & $\begin{array}{l}26(52) \\
8(16) \\
16(32)\end{array}$ \\
\hline 4 & $\begin{array}{l}\text { Negative symptom profile } \\
\text { a. Flat affect } \\
\text { b. Alogia } \\
\text { c. Avolition } \\
\text { d. Anhedonia } \\
\text { e. Inattention }\end{array}$ & $\begin{array}{l}18 \\
19 \\
26 \\
22 \\
20\end{array}$ & $\begin{array}{l}16 \\
13 \\
14 \\
16 \\
16\end{array}$ & $\begin{array}{l}34(68) \\
32(64) \\
40(80) \\
38(76) \\
36(72) \\
\end{array}$ \\
\hline
\end{tabular}

Among the study subjects, $36(72 \%)$ showed difficulties in relationship with friends, $35(70 \%)$ showed inattentiveness, impersistence at work, intimacy and closeness difficulties; 33 (66\%) showed physical anergia, 28 (56\%) showed social inattentiveness and $26(52 \%)$ showed poverty of speech

On SANS, most marked negative symptom is impersistence at work. Most common negative symptom domain is avolition, symptoms are decreased recreational interests and activities as well as poor relationships (Table 3 ).

Table 3: SANS Individual items

\begin{tabular}{|c|c|c|c|c|c|c|c|}
\hline \multirow[t]{2}{*}{ S. No } & \multirow[t]{2}{*}{ SANS item } & \multicolumn{3}{|c|}{$\begin{array}{c}\text { Gender } \\
\text { Distribution }\end{array}$} & \multicolumn{3}{|c|}{$\begin{array}{l}\text { Severity of } \\
\text { symptoms }\end{array}$} \\
\hline & & $\begin{array}{l}\text { Males } \\
\mathrm{n}(\%)\end{array}$ & $\begin{array}{c}\text { Females } \\
\mathrm{n}(\%)\end{array}$ & Total n (\%) & $\begin{array}{c}\text { Absent } \\
\mathrm{n}(\%)\end{array}$ & $\begin{array}{c}\text { Moderate } \\
\mathrm{n}(\%)\end{array}$ & $\begin{array}{c}\text { Marked } \\
\mathrm{n}(\%)\end{array}$ \\
\hline 1 & $\begin{array}{l}\text { Unchanging facial } \\
\text { expression }\end{array}$ & $12(42 \%)$ & $12(54 \%)$ & $24(48 \%)$ & $26(52 \%)$ & $16(32 \%)$ & $\begin{array}{c}08 \\
(16 \%) \\
\end{array}$ \\
\hline 2 & $\begin{array}{l}\text { Decreased spontaneous } \\
\text { movements }\end{array}$ & $8(28 \%)$ & $5(22 \%)$ & $13(26 \%)$ & $37(74 \%)$ & $07(14 \%)$ & $\begin{array}{c}06 \\
(12 \%)\end{array}$ \\
\hline 3 & $\begin{array}{l}\text { Paucity of expressive } \\
\text { gestures }\end{array}$ & $10(35 \%)$ & $6(22 \%)$ & $16(26 \%)$ & $34(68 \%)$ & $11(22 \%)$ & $05(10 \%)$ \\
\hline 4 & Poor eye contact & $9(32 \%)$ & $10(45 \%)$ & $19(38 \%)$ & $31(62 \%)$ & $11(22 \%)$ & $08(16 \%)$ \\
\hline 5 & Affective non responsivity & $5(17 \%)$ & $9(40 \%)$ & $14(28 \%)$ & $36(72 \%)$ & $10(20 \%)$ & $04(8 \%)$ \\
\hline 6 & Lack of vocal inflections & $7(25 \%)$ & $7(31 \%)$ & $14(28 \%)$ & $36(72 \%)$ & $10(20 \%)$ & $04(8 \%)$ \\
\hline 7 & Poverty of speech & $15(53 \%)$ & $11(50 \%)$ & $26(52 \%)$ & $24(48 \%)$ & $15(30 \%)$ & $11(22 \%)$ \\
\hline
\end{tabular}




\begin{tabular}{|l|l|c|c|c|c|c|c|}
\hline 8 & $\begin{array}{l}\text { Poverty of content of } \\
\text { speech }\end{array}$ & $4(14 \%)$ & $5(22 \%)$ & $9(18 \%)$ & $41(82 \%)$ & $08(16 \%)$ & $01(2 \%)$ \\
\hline 9 & Thought blocking & $4(14 \%)$ & $4(18 \%)$ & $8(16 \%)$ & $42(84 \%)$ & $06(12 \%)$ & $02(4 \%)$ \\
\hline 10 & $\begin{array}{l}\text { Increased latency of } \\
\text { response }\end{array}$ & $11(39 \%)$ & $5(22 \%)$ & $16(32 \%)$ & $34(68 \%)$ & $12(24 \%)$ & $04(8 \%)$ \\
\hline 11 & Grooming and hygiene & $17(60 \%)$ & $7(31 \%)$ & $24(48 \%)$ & $26(52 \%)$ & $17(34 \%)$ & $07(14 \%)$ \\
\hline 12 & Impersistence at work & $23(82 \%)$ & $12(54 \%)$ & $35(70 \%)$ & $15(30 \%)$ & $04(8 \%)$ & $31(62 \%)$ \\
\hline 13 & Physical anergia & $21(75 \%)$ & $12(54 \%)$ & $33(66 \%)$ & $17(34 \%)$ & $05(10 \%)$ & $28(56 \%)$ \\
\hline 14 & $\begin{array}{l}\text { Recreational interests and } \\
\text { activities }\end{array}$ & $20(71 \%)$ & $16(72 \%)$ & $36(72 \%)$ & $14(28 \%)$ & $13(26 \%)$ & $23(46 \%)$ \\
\hline 15 & Sexual activity & $17(60 \%)$ & $12(54 \%)$ & $29(58 \%)$ & $21(42 \%)$ & $10(20 \%)$ & $19(38 \%)$ \\
\hline 16 & Intimacy and closeness & $22(78 \%)$ & $13(59 \%)$ & $35(70 \%)$ & $15(30 \%)$ & $14(28 \%)$ & $21(42 \%)$ \\
\hline 17 & Relationships with friends & $22(78 \%)$ & $14(63 \%)$ & $36(72 \%)$ & $14(28 \%)$ & $15(30 \%)$ & $21(42 \%)$ \\
\hline 18 & Social inattentiveness & $15(53 \%)$ & $13(59 \%)$ & $28(56 \%)$ & $22(44 \%)$ & $12(24 \%)$ & $16(32 \%)$ \\
\hline 19 & Inattentiveness during MSE & $20(71 \%)$ & $15(68 \%)$ & $35(70 \%)$ & $15(30 \%)$ & $08(16 \%)$ & $27(54 \%)$ \\
\hline
\end{tabular}

In the present study negative symptoms were more often seen in unmarried subjects, literate subjects, unemployed subjects, joint families, gradual onset of illness, duration of illness between 13-24 months and in relapse cases.

Table 4

\begin{tabular}{|c|c|c|c|c|c|c|}
\hline S. No & Parameter & $\begin{array}{c}\text { Flat affect } \\
\text { n }(\%)\end{array}$ & $\operatorname{Alogia} n(\%)$ & $\begin{array}{c}\text { Avolition n } \\
(\%)\end{array}$ & $\begin{array}{c}\text { Anhedonia n } \\
(\%)\end{array}$ & $\begin{array}{c}\text { Inattention n } \\
(\%)\end{array}$ \\
\hline 1 & $\begin{array}{l}\text { Marital status } \\
\text { a. } \quad \text { Married } n=26 \\
\text { b. } \quad \text { Unmarried } n=25 \\
\text { c. } \quad \text { Others } n=9\end{array}$ & $\begin{array}{l}18(69.2) \\
12(80) \\
4(44.4)\end{array}$ & $\begin{array}{c}15(57.6) \\
11(73.3) \\
6(66.6)\end{array}$ & $\begin{array}{c}20(76.9) \\
13(86.6) \\
7(77.7)\end{array}$ & $\begin{array}{c}19(73.07) \\
12(80) \\
7(77.7)\end{array}$ & $\begin{array}{l}18(69.2) \\
10(66.6) \\
8(88.8)\end{array}$ \\
\hline 2 & \begin{tabular}{ll}
\multicolumn{2}{l}{ Education } \\
a. $\quad$ Literate $n=36$ \\
b. $\quad$ Illiterate $n=14$
\end{tabular} & $\begin{array}{l}24(66.6) \\
10(71.4)\end{array}$ & $\begin{array}{c}25(69.4) \\
7(50)\end{array}$ & $\begin{array}{c}32(88.8) \\
8(57.1)\end{array}$ & $\begin{array}{c}29(80.5) \\
9(64.2)\end{array}$ & $\begin{array}{c}29(80.5) \\
9(64.2)\end{array}$ \\
\hline 3 & $\begin{array}{l}\text { Occupation } \\
\text { a. } \quad \text { Employed } n=17 \\
\text { b. } \quad \text { Unemployed } n=33\end{array}$ & $\begin{array}{l}11(64.7) \\
23(69.6)\end{array}$ & $\begin{array}{l}10(58.8) \\
22(66.6)\end{array}$ & $\begin{array}{l}13(76.4) \\
27(81.8)\end{array}$ & $\begin{array}{l}10(58.8) \\
28(84.8)\end{array}$ & $\begin{array}{l}10(58.8) \\
26(78.7)\end{array}$ \\
\hline 4 & $\begin{array}{l}\text { Family } \\
\text { a. Nuclear } n=36 \\
\text { b. Joint } n=12 \\
\text { c. Single } n=2\end{array}$ & $\begin{array}{c}25(69.4) \\
8(66.6) \\
1(50)\end{array}$ & $\begin{array}{c}22(61.1) \\
10(83.3) \\
0\end{array}$ & $\begin{array}{c}29(80.5) \\
10(83.3) \\
1(50)\end{array}$ & $\begin{array}{c}27(75) \\
10(83.3) \\
1(50)\end{array}$ & $\begin{array}{c}27(75) \\
9(75) \\
0\end{array}$ \\
\hline 5 & $\begin{array}{l}\text { Onset of illness } \\
\text { a. } \quad \text { sudden } n=15 \\
\text { b. } \quad \text { gradual } n=35\end{array}$ & $\begin{array}{c}12(80) \\
22(62.8)\end{array}$ & $\begin{array}{l}10(66.6) \\
22(62.8)\end{array}$ & $\begin{array}{l}10(66.6) \\
30(85.7)\end{array}$ & $\begin{array}{l}10(66.6) \\
30(85.7)\end{array}$ & $\begin{array}{l}11(73.3) \\
25(71.4)\end{array}$ \\
\hline 6 & $\begin{array}{l}\text { Duration of illness in } \\
\text { months } \\
\text { a. } 1-12 n=35 \\
\text { b. } 13-24 n=2 \\
\text { c. }>24 n=13\end{array}$ & $\begin{array}{l}25(71.4) \\
2(100) \\
7(53.8) \\
\end{array}$ & $\begin{array}{l}22(62.8) \\
2(100) \\
8(61.5)\end{array}$ & $\begin{array}{c}26(74.2) \\
2(100) \\
12(92.3)\end{array}$ & $\begin{array}{c}24(68.5) \\
2(100) \\
12(92.3)\end{array}$ & $\begin{array}{l}25(71.4) \\
2(100) \\
9(69.2) \\
\end{array}$ \\
\hline 7 & \begin{tabular}{l}
\multicolumn{2}{l}{ Treatment status } \\
a. Naïve $n=26$ \\
b. Relapse $n=8$ \\
c. On treatment $n=16$
\end{tabular} & $\begin{array}{l}16(61.5) \\
7(87.5) \\
11(68.7)\end{array}$ & $\begin{array}{c}17(65.3) \\
4(50) \\
11(68.7)\end{array}$ & $\begin{array}{l}22(84.6) \\
7(87.5) \\
11(68.7)\end{array}$ & $\begin{array}{c}20(76.9) \\
7(87.5) \\
11(68.7)\end{array}$ & $\begin{array}{c}19(73.07) \\
7(87.5) \\
10(62.5)\end{array}$ \\
\hline
\end{tabular}

On BPRS scores most of the subjects had very mild illness. Basal BPRS scores are 26.04, first follow up BPRS scores were14.62, second follow up BPRS scores were 7.52.[p value $<0.05$, statistically significant]. Basal SANS scores were 43.64, first follow up SANS score were 33.34, second follow up SANS score were 27.08, [p value $<0.05$, statistically significant]. BPRS and SANS scores improved on follow up evaluations after initiation of treatment ( $p$ value $<0.05$ ). Usually positive symptoms improve more effectively with treatment rather than negative symptoms. 


\section{Discussion}

Epidemiological data support the notion that patients with the deficit syndrome represent a distinct subgroup within schizophrenia. In clinical samples, patients with the deficit form of schizophrenia or primary negative symptoms represent about 20\%-30\% of patients, where as in population-based samples approximating incidence samples, patients with the deficit form of schizophrenia comprise $14 \%-17 \%$ of patients with schizophrenia. Carpenter and colleagues examined the prevalence of deficit syndrome within an outpatient clinical population. They reported $19 \%$ prevalence rate in a nonrandom population of patients. Bottlender and colleagues reported a similar prevalence $(26 \%)$ in patients who were evaluated 15 years after their first hospitalization.

The present study is comparable to the existing work done by Vijay et al, ${ }^{24}$ where most of the male subjects are in age groups between 15-35 years and female subjects are almost equally distributed in ages 15-65 years. Similar results were noted in other domains like marital status, education, occupation.

In the present study the most frequently occurring negative symptom domain is avolition followed by anhedonia, while in Chaturvedi et $\mathrm{al}^{25}$ it was affective flattening followed by anhedonia and avolition.

In Chaturvedi et al study patients with schizophrenia showed more of affective flattening, alogia and they were statistically significant, global rating on anhedonia asociatily sub scale had no significant difference, since large number of depressives as well as schizophrenics scored high on this sub scale.

In the present study the most common negative symptom noted on SANS is decreased interest in recreational activities and decreased relationships, where as in study by Kulhara et $\mathrm{al}^{26}$ the most common symptoms were impersistence at work, decreased interests in recreational activities and decreased relationships. In both the studies, the most marked SANS item is impersistence at work.

In the present study $26 \%$ of the study subjects were having significant scores on BPRS which is comparable with the study done by Wijesundara et al. ${ }^{27}$

Usually positive symptoms improve more effectively with treatment rather than negative symptoms. In the present study follow up evaluations of BPRS and SANS scores improved after initiation of treatment which were statistically significant.

Studies by Shtasel et al(1992), Ring et al(1991), Cowell et al(1996), Maric et al(2003) and Szymansky et al (1995) have reported predominant negative symptoms in male though Andia et al(1995), Usall et al(2001) and Lindamer et al (1999) reported no gender differences in expression of negative symptoms. No such comparison was done in our study. Such conflicting results might be attributed to difference in rating scales employed.

In study by Pogue-Guile and Harrow schizophrenia patients have shown more poverty of speech. Other negative symptoms is poor physical hygiene, impersistence at work, inattention and inability to feel intimacy were observed more in subjects with schizophrenia.

\section{Limitations of the Study}

Limitations of the present study are small sample size and lack of focus on premorbid personality. Some patients were treatment naïve, some with relapse while some were on treatment as the sample was collected on outpatient basis. This is a heterogeneous sample which is a shortcoming. This study is not a prospective study. Hence, patients were reviewed in a short duration that is 2 weeks and 4 weeks. Improvement with treatment was seen in BPRS and SANS scores in the follow up visits compared to baseline scores.

\section{Conclusion}

In the present study negative symptoms had a significant association with demographic parameters like education and occupation. In majority of the subjects duration of illness is less than one year and the negative symptoms started quite early in the course of the disease contrary to the popular evidence. In the present study there is an equal distribution of symptoms in all five domains of negative symptoms with 'avolition' at the top.

Occurrence of negative symptoms is quite frequent, with decreased relationships and decreased interest in recreational activities topping the list. Clinically negative symptoms were missed in few subjects, as is the case in general. So it is advisable to employ standard rating scales in all clinical evaluations, lest one should overlook the negative symptoms.

In the present study most of the cases were treatment naïve. Follow up evaluations in all showed the negative symptoms responding effectively to treatment, contrary to the existing evidence regarding their refractoriness.

Negative symptoms are intrinsic to the pathology of schizophrenia and are associated with significant deficits in motivation, verbal and nonverbal communication, affect, cognitive and social functioning. ${ }^{18}$ This in turn contributes to poor outcome, response to treatment and social adjustment. ${ }^{19}$ Negative symptoms in schizophrenia enjoy a prominent place in today's clinical practice and research as a distinct and integrated entity in symptomatology.

As the study of negative symptoms assumes immense significance in schizophrenia research it is imperative and desirable to make the study designs more comprehensive and foolproof.

\section{Acknowledgement}

We personally thank Dr. Srilakshmi Pingali, Associate Professor of Psychiatry, Gandhi Medical College, Hyderabad for being Incharge editor of this article. We thank all the patients and their family members for being part of this study. 


\section{Source of Funding}

None.

\section{Conflict of Interest}

Nil.

\section{References}

1. Sadock B J, Kaplan \& Sadock's Comprehensive Text Book of Psychiatry, $9^{\text {th }}$ edition, vol1, USA., Lipincott Williams \& Wilkins, 2009, Chapter 12.

2. India support to schizophrenia, country project of support to people with schizophrenia, World Health Organization, April 2004 (last visited on 05.06.2019)

3. Lambert M, Naber D, Current schizophrenia, $3^{\text {rd }}$ edition, London, Springer Health Care Ltd, 2012, chapter 1.

4. Tendon R, Keshavan MS, Nasrallah HA, Schizophrenia, "Just the facts": What we know in 2008, part 1: overview. Schizophre Res. 2008;100:4-19.

5. Max Hamilton, Fish's Clinical Psychopathology, Signs \& symptoms in Psychiatry, Second Edition, England, John Wright \& sons Ltd., 1968, Chapter 3\&4.

6. Buckley PF., Psychiatric clinics of North America, Schizophrenia, Pennsylvania, Elsevier Inc., September 2012, 35(3).

7. The ICD-10 Classification of Mental and Behavioral Disorders (ICD), $10^{\text {th }}$ edition, Clinical descriptions and diagnostic guidelines, W.H.O., Geneva, 2007.

8. Diagnostic and Statistical Manual of mental disorders (DSM 5), $5^{\text {th }}$ edition, Washington, American Psychiatric Association 2013.

9. Saddock BJ, Kaplan \& Saddock's synopsis of psychiatry, Behavioral sciences and clinical psychiatry, $10^{\text {th }}$ edition, U.S.A., Lippincott Wilkins \& Williams, 2007, Chapter 13.

10. Gelder MG., Andreasen NC, New Oxford Text Book of Psychiatry, 2nd edition, Vol 1, U.S.A., Oxford University Press Inc., New York, 2009, Chapter 4.3

11. Sajatovic M, Ramirez LF. Rating scales in mental health, second edition, U.S.A., Lexi Comp Inc, 2003.

12. Mortimer AM. Symptom rating scales and outcome in schizophrenia, Brit J Psychiat, 2007, 191,s 7-14.

13. Iager AC, Kirch DG, R J Wyatt RJ. A negative symptom rating scale. Psychiat Res. 1985;16:27-36.
14. Kay SR, Opler LA, Lindenmayer JP. The positive and negative syndrome scale (PANSS): Rationale and standardization. Br J Psychiatry. 1989;155suppl.7):59-65.

15. Andreasen NC. Scale for Assessment of Negative Symptoms (SANS). Iowa City: University of Iowa,1981.

16. Andreasen NC. This week's Citation Classic, Negative symptoms in schizophrenia, Current contents, November 29,1993,48.

17. Andreasen NC. Negative symptoms in Schizophrenia: definition and reliability. Arch Gen Psychiatry. 1982,39:784-8.

18. Robert H, Sarah B, EGOFORS Research group, IMPACT OF Negative symtoms on Psychosocial Functioning in Schizophrenia, PsyRING, University of Glasgow, NHS.

19. Earnst K, Kring A. Construct validity of negative symptoms: an empirical and conceptual review. Clin Psychol Rev. 1997;17(2):167-89.

20. Buschbaum MS. Anteroposterior gradients in cerebral glucose use in schizophrenia and affective disorders. Arch Gen Psychiatry. 1984,41:1159-66.

21. Ingvar DH, Frazen G. Abnormalities of cerebral bold flow distribution in patients with chronic schizophrenia. Acta Psychiatry Scand. 1974;50:425-62.

22. Chouinard G, Jones BD. Schizophrenia as dopamine deficiency disease. Lancet. 1978;1:99-100.

23. Jambur A. Negative symptoms: Psychopathological models. $J$ Psychiatry Neurosci. 1991;16(1).

24. Vijay, Sinha VK. Gender difference in symptoms profile of Schizophrenia. Indian Assoc Soc Psychiatry. 2009;25(34):106-10.

25. Chaturvedi.SK. Negative symptoms in Schizophrenia and Depression. Indian J Psychiatry. 1985;27(3):237-41.

26. Kulhara P. Negative and depressive symptoms in Schizophrenia. Br J Psychiatry. 1989;154:207-11.

27. Wijesundara H. Psychopathology in patients with schizophrenia attending a psychiatry outpatient clinic at a tertiary care hospital, SL. J Psychiatry. 2011;2(1):23-7.

How to cite this article: Phanikanth $\mathrm{K}$, Sai Krishna P, Datt M. Study of negative symptoms in schizophrenia. Telangana J Psychiatry. 2020;6(1):34-39. 